\title{
Burn injuries in the Eastern Province of Sri Lanka: an analysis and outcome in a tertiary care hospital, Batticaloa
}

\author{
Selladurai Pirasath ${ }^{1}$, Velapoddy Jasotharan ${ }^{2}$, Peethamparam Jeepara ${ }^{3}$ \\ 1 Post Intern Medical Officer, Teaching Hospital Batticaloa, Sri Lanka. \\ 2 Medical Student, Faculty of Health Care Sciences, Eastern University of Sri Lanka. \\ 3 Consultant Surgeon, Teaching Hospital Batticaloa, Sri Lanka.
}

\begin{abstract}
Introduction: A high number of accidental and self-burn injuries are experienced in Batticaloa. This study was performed to evaluate the epidemiology, types, treatment and outcome of patients with burn injuries admitted to surgical units at the Teaching Hospital, Batticaloa.

Methods: Data were collected by interviewer administered questionnaires from all patients admitted with burn injuries to surgical units during the period 1 August 2011 to 31 March 2012 and analysed using the SPSS analytical package.

Results: Thirty nine (62\%) of 63 victims were female; 67\% were less than 40 years and $73 \%$ were married. Burn injuries were common (62\%) in rural areas. The majority race was Tamil (81\%), 14\% were Muslim and 5\% Sinhalese (5\%). Accidental burn injuries (35, 56\%) occurred more frequently than suicidal injuries (26, 41\%). Some 3\% were homicidal burn injuries. Use of traditional lamps $(18,51 \%)$ and kerosene oil cookers $(9,26 \%)$ were the main causes for accidental burn injuries. Psychological problems (6\%), alcoholism (10, 16\%) and epilepsy (3\%) were risk factors for accidental burn injuries. Marital conflict $(14,54 \%)$ and courtship failure $(6,23 \%)$ were the significant $(p<0.05)$ main contributors to suicidal burn injuries. Deep burns (73\%) were common. Almost all patients required strong analgesics and prophylactic antibiotics. Skin graft (40\%) was the mainstay of surgical treatment. Wound infections (52, 82\%) were the commonest complication. Burn mortality was $15 \%$ (10). Mortality was greatest $(7,11 \%)$ for accidental burns during the second week of hospital stay, and was due to infection.
\end{abstract}

Conclusion: Accidental burn injuries were more common than suicidal injuries. Traditional lamps and kerosene oil cookers were the main causes for accidental injuries. Marital problems and courtship failure significantly contributed to suicidal burn injuries.

Key words: Burns; Suicide; Batticaloa.

\section{Introduction}

A burn is an injury to flesh caused by heat, electricity, chemicals, light, radiation or friction [1,2,3]. Most burns only affect the skin (epidermal tissue and dermis). Rarely, deeper tissues such as muscle, bone, and blood vessels may also be injured. Burns may be treated with first aid, in an out-of-hospital setting, or may require more specialised treatment in specialised burn centers.

The Batticaloa General Hospital is a large government health facility in the east coast of Sri Lanka with a bed strength of 700. The district's population of half a million is mostly rural. Ethnic Tamils (Hindus and Christians) comprise the majority (74\%), with a Muslim minority

Correspondence: Dr. Peethambaram Jeepara, Consultant

Surgeon, Teaching Hospital, Batticaloa, Sri Lanka

E-mail: jeepara@yahoo.com accounting for $25 \%$ (the Muslims are considered a separate ethnic group in Sri Lanka). The hospital catchment area includes the whole of Batticaloa district and extends to the neighbouring district of Amparai. Although not having a specialised burn unit, this is the only referral hospital for severe burns in the area; patients are admitted to general surgical wards, each of which has a burn section. The country's only burn centre in the capital city is an 8 h-drive away, and patients are not transferred to that facility. The high number of self-burn injuries, often ending in death, drew the attention of surgeons from "Doctors without Borders", a voluntary international organization, and of the hospital psychiatrist. This was a study of the epidemiology, outcome and psychosocial aspects of patients with burn injuries admitted to surgical units, Teaching Hospital, Batticaloa to get a better understanding of the extent and possible causes of the phenomenon.

\section{Materials and methods}

Interviewer administered pre-designed questionnaires 
were given to all patients admitted with burn injuries to surgical units, at the Teaching Hospital, Batticaloa during the period 1 August 2011 to 31 March 2012. All those in the study gave informed written consent. Ethical approval for the study was obtained from the Ethical Review Committee, Faculty of Health Care Science, Eastern University, Sri Lanka. Data were analysed using the SPSS analytical package, using a Chi-squared test.

\section{Results}

\section{Patient demographics}

Thirty nine (62\%) of 63 victims were female; four were pregnant. Sixty seven percent were less than 40 years (Table 1). Seventy three percent were married. The incidence was more in rural areas (39, 62\%) compared with urban areas. The majority was Tamil $(51,81 \%)$ and the rest were Muslim (9, 14\%) or Sinhalese (3, 5\%).

\section{Pattern of Burn Injuries}

Accidental burn injuries (35, 56\%) were more than suicidal injuries (26, 41\%) while homicidal burn injuries (2, $3 \%)$ were also reported. Deep burns (46, 73\%) occurred more frequently compared with superficial burns (Table 2 ). The median extent of burn was $40 \%$ of total body surface area (TBSA) in the majority (38, 60\% -Table 3). Thermal burns (56, 89\%), chemical burns (3, 5\%) and electrical burns $(4,6 \%)$ comprised the aetiology while fire burn injury (56, 89\%) was a common method of suicidal and accidental burn injuries.

\section{Factors contributing to burn injury}

Traditional lamps $(18,51 \%)$ and kerosene oil cookers $(9$, 26\%) were the main sources of accidental burn injuries. Furthermore, additional contributory factors were psychological problems (4, 6\%), alcoholism (10, 16\%) and epilepsy (2, 3\% -Table 4). By contrast, marital problems $(14,54 \%)$ and courtship failure $(6,23 \%)$ contributed to suicidal burn injuries (Table 5). Most who had suicidal burn injuries used it as a form of threat, and were afraid of death.

\section{Treatment and outcome}

Almost all patients needed strong analgesics and needed cover of prophylactic antibiotics. Skin graft (25, 40\%) was the mainstay of treatment. Wound infections (52, 82\%) were the commonest complication and a proportion (10, $16 \%)$ developed systemic infections during the course of their illness. Survivors had long hospital stays of more than two weeks - 30 (48\%) stayed in hospital for three weeks. Contractures, especially in the neck and limbs, were reported during follow up of our patients resulting in considerable cosmetic disfigurement. Ten (15\%) patients died. Mortality was greatest $(7,11 \%)$ for accidental burns during the second week of hospital stay due to infection.

Traditional lamps and kerosene oil cookers were significantly associated with accidental burn injuries $(\mathrm{P}<0.05$, Chi Square) while marital disharmony and courtship failure were significantly associated with the suicidal burn injuries $(\mathrm{P}<0.05$, Chi Square). Mortality and morbidity were significantly associated with infections, not the total surface area of burn injuries ( $\mathrm{P}<0.05$, Chi Square).

\section{Discussion}

At 30.1 per 100,000 inhabitants, the suicide rate in Sri Lanka is one of the highest in the world [4]. Agrochemical poisoning is reported as the most common method of suicide in the country, followed by poisonous seeds, hanging, deliberate train injury and self drowning. Self-immolation is generally thought to be less common. In our study, burn injuries contributed to suicide among a high proportion of young married women in the Batticaloa district. In Sri Lanka itself, only 17 (3\%) suicides were attributed to burns in a retrospective study using coroner's reports in a 10-year-period in the northern district of the country [5].

Mostly men and older people committed suicide and those who committed deliberate self-harm were young women [6]. This was noted in our study too. Most were married and had children who selected self-immolation by fire as their method of suicide regardless of their children. Most patients who attempted suicide did not want to die and used these methods to receive attention and to threaten their partners. The older age people chose the fire burn method to end their life because of chronic ill health and lack of social support.

Very few of those who attempted suicide by fire had a previous mental illness, as compared to the West, where most suicidal burn patients suffered from severe psychotic illnesses [7]. In our patients, the social make-up and poor problem-solving ability may be contributing factors. We believe that problem-solving ability has to be improved among young married adult women as a coping strategy. By contrast, accidental burn injuries were noted significantly among poor people who lived in rural areas, where, the traditional lamp was the main cause of their burn injuries. As such, encouraging the use of modern lamps may reduce the incidence of burn injuries.

The percentage BSA involved in burn injuries was high among suicidal burn injuries compared to accidental burn injuries. Self-inflicted burns were much more extensive, and had high mortality compared with accidental burns. The fact that the clothes had been impregnated with a fire accelerant explains the size and depth of these burns. Suicidal burn injuries also had high mortality and morbidity because the percentage BSA involved was high. 
Infections were common among them. There was positive correlation with infections and suicidal burn injuries which may have been due to a breach in the skin barrier in deep burn injuries.

Infections were the mainstay of death among burn injuries commonly during the second week of illness which prolonged hospital stay. While large burns can be fatal, modern treatments developed in the last 60 years have significantly improved the prognosis of such burns, especially in children and young adults [8]. In the United States, approximately four of every 100 people with injuries from burns will succumb to their injuries. The majority of these fatalities occur either at the scene or en-route to hospital [9]. However, lack of specialized intensive burn care in this institution mainly contributed to the infections in most cases. Precautions to prevent infections are necessary to reduce the mortality and morbidity of these patients.

People, who set fire to themselves following a conflict, hope it might be solved and sometimes it is. Unfortunately, the use of such a dangerous method of deliberate self-harm means that many will die [10]. And, of course, the scarring and contractures cause many new problems for burn injury survivors, creating social phobia.

\section{Conclusion}

Accidental burn injuries were the most common burn injury in our study and traditional lamps and kerosene oil cookers were the main causes of such accidents. Suicidal burns were mainly encountered among women where marital disharmony and courtship failure were the main causes. In Batticaloa, use of fire was a common method of accidental and suicidal burn injuries. Mortality due to infections was greatest for accidental burns during the second week of hospital stay in our patients.

\section{Recommendations}

Precautions should be taken to prevent the incidence of accidental burn injuries and problem-solving ability has to be promoted to reduce the rate of suicidal burn injuries among young females in the Batticaloa district.

\section{Acknowledgements}

The staff of the Teaching Hospital Batticaloa were extremely helpful and made available to us the records to gather information on the reported cases of burn injuries in surgical units. We thank them for their support. We would also like to thank the patients who provided the information without which this report could not have been pre- pared. Despite their hardships and poverty, every one of them, without exception, gave us their unstinted help sharing their worries, concerns, aspirations and hopes.

\section{References}

1. MedlinePlus. 'Burns'. Available at: http://www.nlm.nih.gov/medlineplus/burns.html. Retrieved - 22 November 2010.

2. WebMD. 'Burns-Topic Overview'. Firstaid \& Emergencies. http://firstaid.webmd.com/tc/burnstopic-overview. 2009. Retrieved on 22 November 2010.

3. Total Burn Care, 3rd Edition, Edited by David Herndon, Saunders, 2007.

4. Annual Health Bulletin 2000. Department of Health Services, Sri Lanka.

5. Somasundaram D, Rajadurai S. War and suicide in Northern Sri Lanka. Acta Psychiatr Scand 1995; 91: 1-4.

Doi:http://dx.doi.org/10.1111/j.16000447.1995.tb09733.x

PMid:7754779

6. Johnstone EC, Freeman CPL, Zealley AK. Companion to psychiatric studies. 6th ed. Edinburgh: Churchill Livingstone, 1998.

7. Cameron DR, Pegg SP, Muller M. Self-inflicted burns. Burns 1997; 23:519-21.

Doi:http://dx.doi.org/10.1016/S03054179(97)00039-9

8. Sevitt S. 'A review of the complications of burns, their origin and importance for illness and death'. J Trauma 1979; 19: 358-69.

Doi:http://dx.doi.org/10.1097/00005373197905000-00010

PMid:448773

9. Factsheet American Burn Association website. Available at: http://www.ameriburn.org/resources_factsheet.php

10. Maniam T. Suicide and para-suicide in a hill resort in Malaysia. British Journal of Psychiatry 1988; 153: 222-5.

Doi: http://dx.doi.org/10.1192/bjp.153.2.222

PMid:3255436 